\title{
Recorregut de recerca geològica i geoambiental per la comarca de l'Anoia: des de Jorba al Pla de Rubió, Rubió i a la Serra de Rubió
}

Josep Maria Mata-Perelló

Joaquim Sanz Balagué

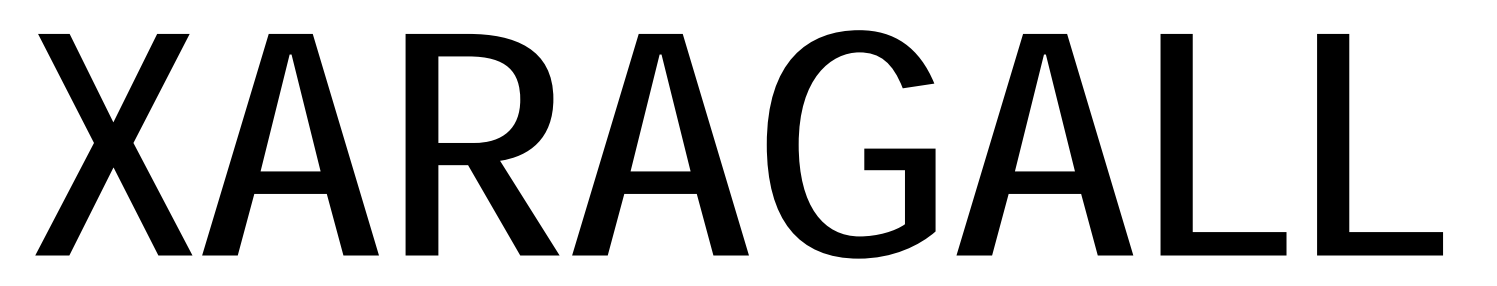

REVISTA DE CIÈNCIES DE LA CATALUNYA CENTRAL

\section{n. 12}

DESEMBRE 2014 


\title{
RECORREGUT DE RECERCA GEOLÒGICA I GEOAMBIENTAL PER LA COMARCA DE L'ANOIA: DES DE JORBA AL PLA DE RUBIÓ, RUBIÓ I A LA SERRA DE RUBIÓ
}

\author{
Josep Maria Mata-Perelló \\ Museu de geologia Valentí Masachs, Escola Politècnica Superior d'Enginyeria de Manresa \\ (EPSEM), Universitat Politècnica de Catalunya · BarcelonaTech (UPC), 08272 Manresa, Spain
}

\section{Joaquim Sanz Balagué}

Departament d'Enginyeria Minera i Recursos Naturals (EMRN), Escola Politècnica Superior d'Enginyeria de Manresa (EPSEM), Universitat Politècnica de Catalunya . BarcelonaTech (UPC), 08272 Manresa, Spain

Paraules clau: Depressió Geològica de l'Ebre, Materials terciaris, Materials quaternaris, Patrimoni miner

\section{Resum}

Itinerari realitzat el 26 de gener de 2014. En aquesta ocasió, es realitzarà un recorregut geològic que discorrerà en la seva totalitat per diferents indrets de la Depressió Geològica de I'Ebre; i més concretament pels sectors corresponents a la seva Depressió Central. D'aquesta manera, tot el recorregut transitarà entre afloraments dels materials terciaris (de l'Eocè i de I'Oligocè) i quaternaris que reblen aquesta depressió. Així, veurem inicialment els afloraments rogencs de la Formació Artés. Tot seguit trobarem els nivells de calcolutites grisenques i dels guixos de Clariana, de la mateixa formació anterior. Finalment, trobarem nivells detrítics, que també pertanyen a la Formació Artés.

Per altra banda, la totalitat del recorregut transitarà per la comarca de l'Anoia, integrant de la Catalunya Central, de principi a fi, des de Jorba al Pla de Rubió, Rubió i la Serra de Rubió, per on finalitzarà aquest recorregut. 


\section{Objectius fonamentals}

Els objectius fonamentals que es pretenen aconseguir en aquest itinerari, es poden concretar en els següents aspectes generals:

1. Observació i descripció dels materials terciaris (exclusivament del Paleogen, i més concretament de l'Eocè i de I'Oligocè) de la Depressió Geològica de l'Ebre (i més exactament de la seva Depressió Central). Així, el recorregut de l'itinerari discorrerà íntegrament entre els afloraments del materials la Formació Artés, (del trànsit de I'Eocè a I'Oligocè), dintre del Complex Al-luvial de l'Anoia. Així, dintre d'aquesta formació, es veuran afloraments de calcolutites, gresos, guixos i conglomerats, segons els diferents indrets del recorregut de l'itinerari.

2. Observació de les estructures locals de la Depressió Geològica de l'Ebre, al llarg del recorregut de l'itinerari.

3. Observació i reconeixement de les mineralitzacions evaporítiques guixoses situades pels voltants de Jorba (els guixos de Clarina de la Formació Artés).

4. Observació de les explotacions relacionades amb els materials anteriors, i amb altres, d'acord amb el sentit de la marxa de l'itinerari.

5. En tots els casos, a les explotacions anteriors, s'observaran les restauracions efectuades en elles, si s'escau.

6. S'observaran, al llarg de tot el recorregut, els diferents elements relacionats amb el Patrimoni Geològic i Miner-

\section{Antecedents}

Pel que fa al recorregut del tram principal del present itinerari, no existeixen gaires antecedents bibliogràfics. Sols n'hi ha pel que fa referencia a la localitat de Jorba. Entre aquests, farem esment dels següents treballs nostres: Mata-Perelló (1997, 1999, 2000, 2001, 2012 i 2014).

Pel que fa a la descripció de les mineralitzacions, seguirem fent esment d'alguns altres treballs nostres: Mata-Perelló (1990 i 1991); el primer relatiu a la comarca de l'Anoia, el segon al conjunt de les mineralitzacions catalanes.

I, finalment, pel que fa a l'estructura geològica de la zona per la qual discorre l'itinerari, farem esment dels treballs de: Guimerà et altri (1982) i de RIBA et altri (1976). També farem esment d’un treball nostre: Mata-Perelló (1985).

Tots aquests treballs referenciats, i d'altres, figuren esmentats per ordre alfabètic a l'apartat dedicat a la BIBLIOGRAFIA. 


\section{Recorregut de l'itinerari}

El recorregut de l'itinerari discorrerà íntegrament per la comarca d'Anoia, des de principi a fi. Així, s'iniciarà a la població de Jorba, per on es faran les dues primeres aturades. Tot seguit, el recorregut es dirigirà cap a l'antiga carretera nacional $\mathrm{N}$ - IIA, anant cap a ponent, fins trobar la carretera autonòmica $C$ - 1412A. Tot i així, aviat es trobarà la carretera local BV - 1037, que es dirigeix cap al poblet de Rubió.

Així, ens caldrà continuar per aquesta carretera, passant primer pel Pla de Rubió i arribant posteriorment a Rubió. En aquest recorregut, de poc més de 5’5 KM, es realitzaran diverses aturades.

Posteriorment, el recorregut es dirigirà cap a la Serra de Rubió; concretament fins a trobar la carretera local BV - 1031 (que enllaça Igualada i els Prats de Rei). EN arribar-hi finalitzarà I'itinerari, després de fer diverses aturades.

\section{Advertiments previs}

Com en altres recorreguts de RECERCA GEOLÒGICA I MINERALÒGICA... si es disposa del temps suficient, poden efectuar-se passant per totes les parades i filloles. En cas contrari, recomanem prescindir de les anomenades PARADES - CONDICIONALS.

També cal tenir en conte que part del recorregut, tant a l'inici de l'itinerari, com als seus darrers trams, es realitzarà per camins de terra, per la qual cosa caldrà prendre les degudes precaucions. En aquest recorregut, caldrà fer petits trams a peu, per alguns indrets de la Serra de Rubió, però seran molt curts.

Cal tenir, com sempre, una cura molt especial de respecte a la natura, al llarg de tot el recorregut de l'itinerari, i també fora d'ell.

\section{Descripció de l'itinerari}

Com de costum, estructurarem el recorregut de l'itinerari en una sèrie de PARADES, que anirem veient. En cadascuna d'aquestes aturades farem un breu comentari (geològic 0 mineralògic, segons s'escaigui). En cada cas indicarem, entre parèntesi, el full topogràfic on es troba l'aturada.

En aquest cas, el recorregut de l'itinerari s'inclourà dintre del següent full, del "Mapa Topográfico Nacional", realitzat a l'escala 1:50.000 per I'"I.G.C. de España": 391 (o d'Igualada). Tanmateix, si s'escau, es pot utilitzar el Mapa Topogràfic Comarcal d'Anoia, editat per I'Institut Cartogràfic de Catalunya.

Així doncs, la relació de les aturades, que composen el recorregut d'aquest itinerari és la següent: 


\subsection{Parada 1. ENTRADA A JORBA PER LA CARRETERA NACIONAL N - IIA, (terme municipal de Jorba, comarca d'Anoia). (Full 391).}

El recorregut del present itinerari el començarem per les immediacions de la població anoienca de Jorba. Així, I'iniciarem a l'entrada de la població venint des d'Igualada per la carretera N IIA.

Jorba es troba situada quasi al bell mig de la comarca d'Anoia, a ponent de la seva capital, la ciutat d'Igualada. Per d'altra banda, es troba ubicada dintre de la Depressió Geològica de I'Ebre, en el sector que fa anys vam denominar com la seva Depressió Central (MATA PERELLÓ, 1985). Així, es troba entre afloraments de materials cenozoics, que constitueixen el seu subsòl.

Efectivament, la població de Jorba (i bona part del seu terme municipal) es troba entre els afloraments dels materials eocens de la Formació Artés (que més amunt són oligocènics). Així. Mirant pels sectors on ara ens trobem, veurem els nivells de les margues i del gresos rogencs de l'esmentada formació. Cal dir que aquest color procedeix de la presencia de petites quantitats d'HEMATITES $\left(\mathrm{Fe}_{2} \mathrm{O}_{3}\right)$. Aquest mineral tenyeix la calcita, el quars i les argiles 8minerals generalment incolors), integrants dels gresos i de les margues. Per d'altra banda, la presencia del $\mathrm{Fe}^{3}$ es indicatiu de que aquest metall es troba oxidat i de que aquests sediments que el contenen són continentals.

Així, ara a l'indret on ens trobem situats, es poden veure els nivells rogencs que acabem d'esmentar. Més amunt, per sobre d'ells, es poden veure els nivells de calcolutites gris blanquinoses i de guixos, que pertanyen als denominats guixos de Clariana (integrats dintre de la Formació Artés). (fotografia 1).

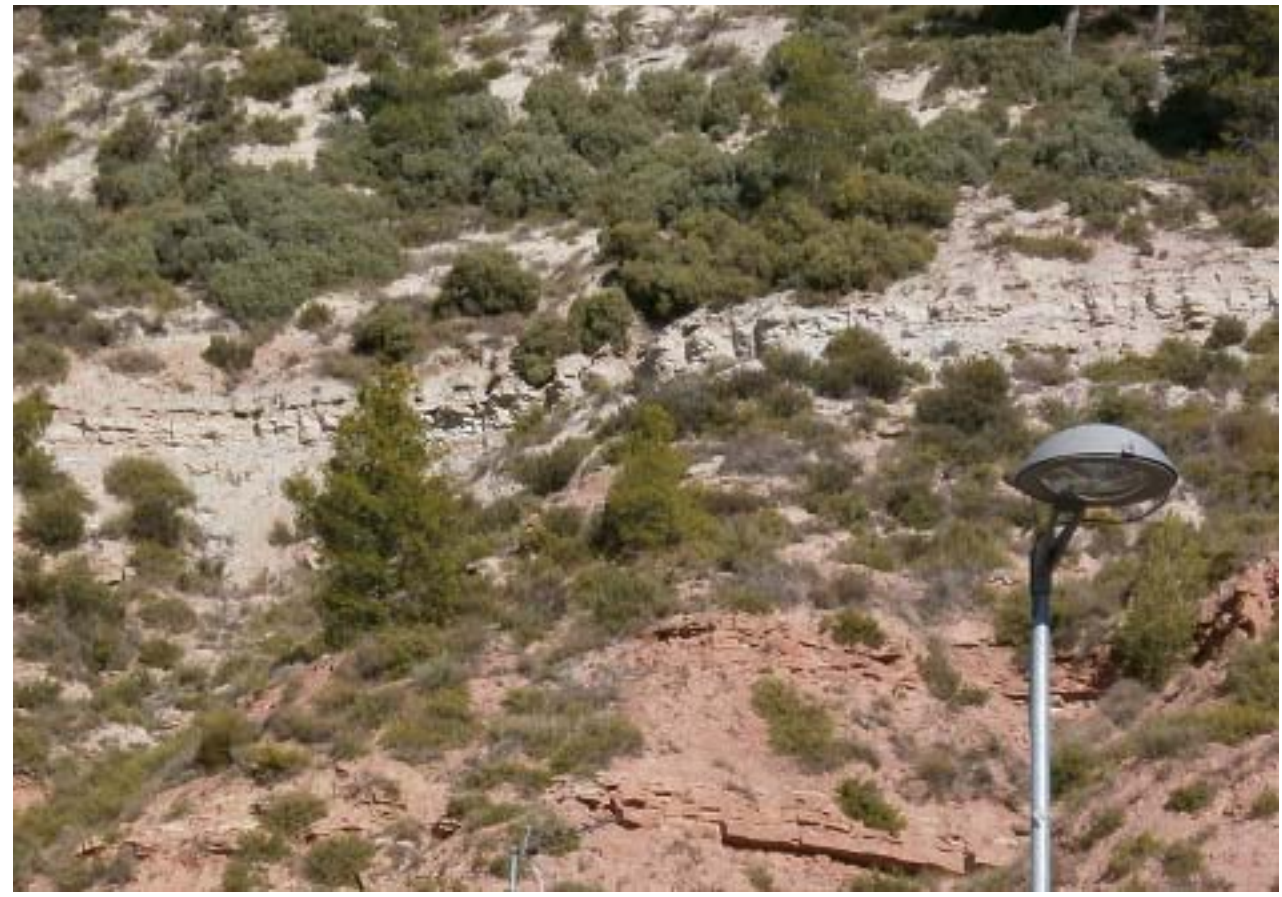

Fotografia 1. Els materials rogencs de la Formació Artés a Jorba. Es fan ostensibles els nivells gresos i els de margues (o calcolutites). Per sobre es veuen els primers nivells dels guixos de Clariana, d'aquesta mateixa formació. Hi apareixen fonamentalment calcolutites (o margues) de tonalitats blanquinoses 
Cal dir també que aquests materials han estat explotats a diferents indrets del terme municipal de Jorba. Així, fins fa poc temps s' han explotat a Sant Genís (a llevant d'on ara som) els nivells de les calcolutites, per tal d'ésser emprades com a material ceràmic. I per d'altra banda, a ponent s' han estat explotant els guixos, com veurem a la propera aturada.

Per altra banda, cal dir que més amunt es veuen terrenys del pleistocè i de l'Holocè, que corresponen a una antiga terrassa fluvial del riu Anoia. Aquests materials són discordants amb els anteriors.

\subsection{Parada 2. INICI DE LA CARRETERA A RUBIÓ, BV - 1037, (terme municipal de Jorba, comarca d'Anoia). (Full 391).}

Després de realitzar la parada anterior, cal sortir de Jorba, per l'antiga carretera $\mathrm{N}$ - IIA, la qual la travessa. Seguint aquesta carretera, arribarem prop de I'Autovia A - 2 i també a la cruïlla d'on surt la carretera autonòmica C - 1412A, la qual es dirigeix cap a Copons i cap Calaf (també cap a Tremp). Així, haurem d'agafar aquesta carretera, anant cap al Nord. Tot i així, ben aviat trobarem el trencall (per la dreta) de la carretera local que es dirigeix cap a Rubió, la carretera BV . 1037. Ens caldrà agafar-la. A uns 50 metres del seu inici, trobarem un caminet (per l'esquera) que podem agafar, parant a l'inici. Fent ara un petit recorregut, d'uns 100 metres, arribarem a un indret, per on podem fer una nova aturada. Així, des de l'anterior, haurem recorregut uns 2' $5 \mathrm{Km}$ i escaig.

En aquest recorregut, hem anat trobant els materials que hem esmentat a l'aturada inicial. Primer, haurem vist els nivells de les calcolutites i gresos vermells de la Formació Artés i després els nivells grisencs. blanquinosos amb nivells de calcolutites, que corresponen als nivells basals dels guixos de Clariana.

Precisament, ara a l'indret de l'aturada, afloren aquests materials acabats d'esmentar, Tot i així, a l'altra banda de la carretera i del riu Anoia, es fan clarament palesos els guixos, els anomenats guixos de Clariana (que també pertanyen a la Formació Artés i al Complex Al-luvial de l'Anoia). Aquests materials han estat explotats fins fa pocs anys en una pedrera. A I'actualitat, la seva explotació es aprofitada com un abocador de residus. Així, des d'aquest indret, la pedrera es fa enormement palesa. (fotografia 2). 


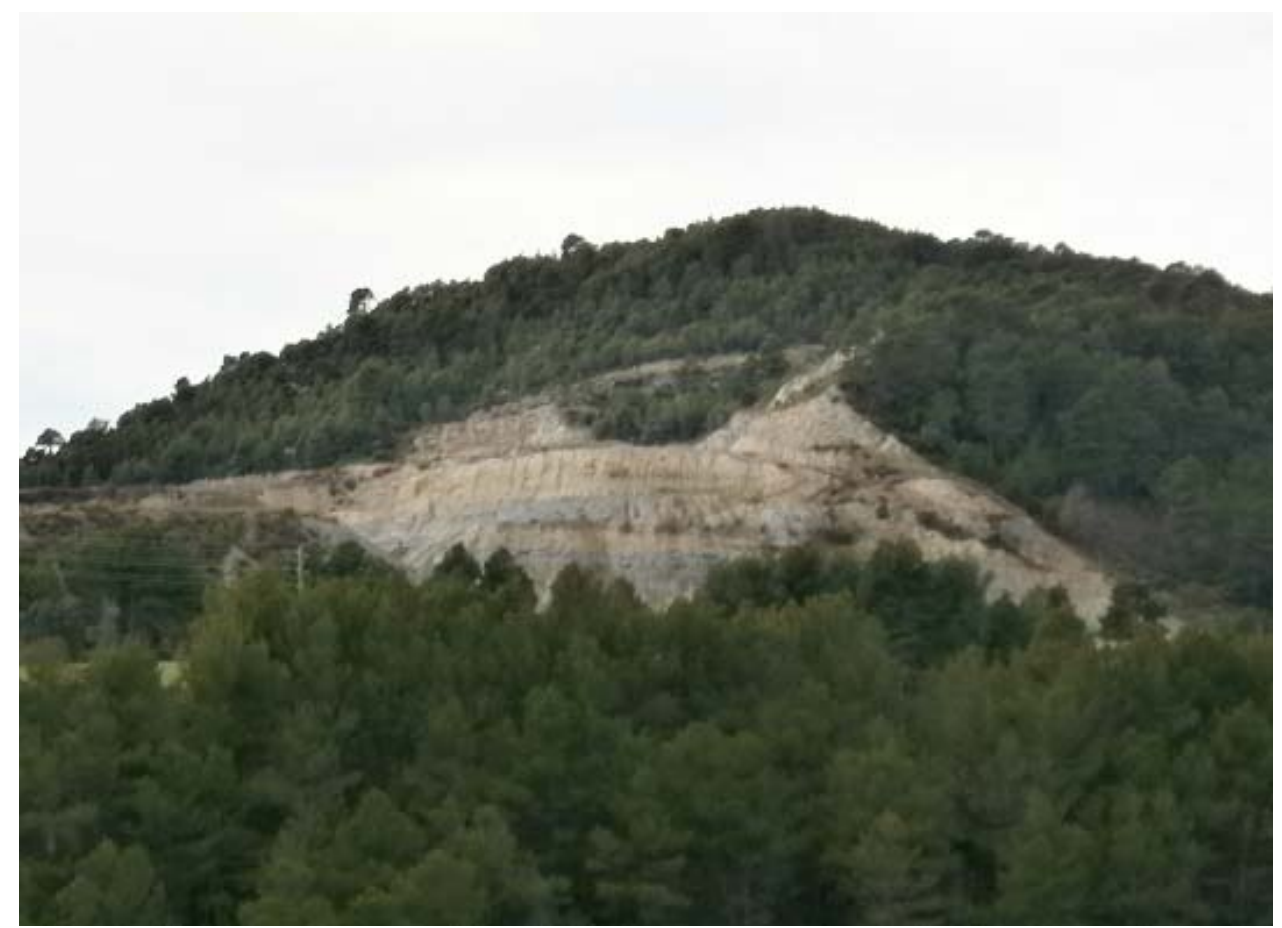

Fotografia 2. Aspecte de I’antiga pedrera de guix de Jorba. Aflorament dels nivells dels guixos de Clariana

Aquesta pedrera, ara aturada i utilitzada com abocador, va ésser una de les més importants de Catalunya. Va pertànyer a l'empresa Vilovigyps i posteriorment a l'empresa Brittis Gypsum, que te diverses explotacions al Sud d’Espanya, com a Sorbas (Almería).

\subsection{Parada 3 - CONDICIONAL. IMMEDIACIONS DEL Km 1, DE LA CARRETERA BV - 1037, (terme municipal de Jorba, comarca d'Anoia). (Full 391).}

Després de fer la parada anterior, cal continuar per la carretera BV - 1037, que hem agafat a la parada anterior i que es dirigeix cap a Rubió. En arribar a les immediacions del $\mathrm{Km} \mathrm{1}$, si s'escau, podem fer una nova aturada. Tot i que es millor fer-la prop del trencall de Cal Cesc. Així, des de la parada anterior haurem fet un desplaçament de $1 \mathrm{Km}$, aproximadament.

En aquest desplaçament, hem continuat trobant els materials esmentats a l'aturada anterior. Efectivament, en aquest trajecte haurem vist afloraments dels guixos al costat de la carretera. (fotografia 3). 


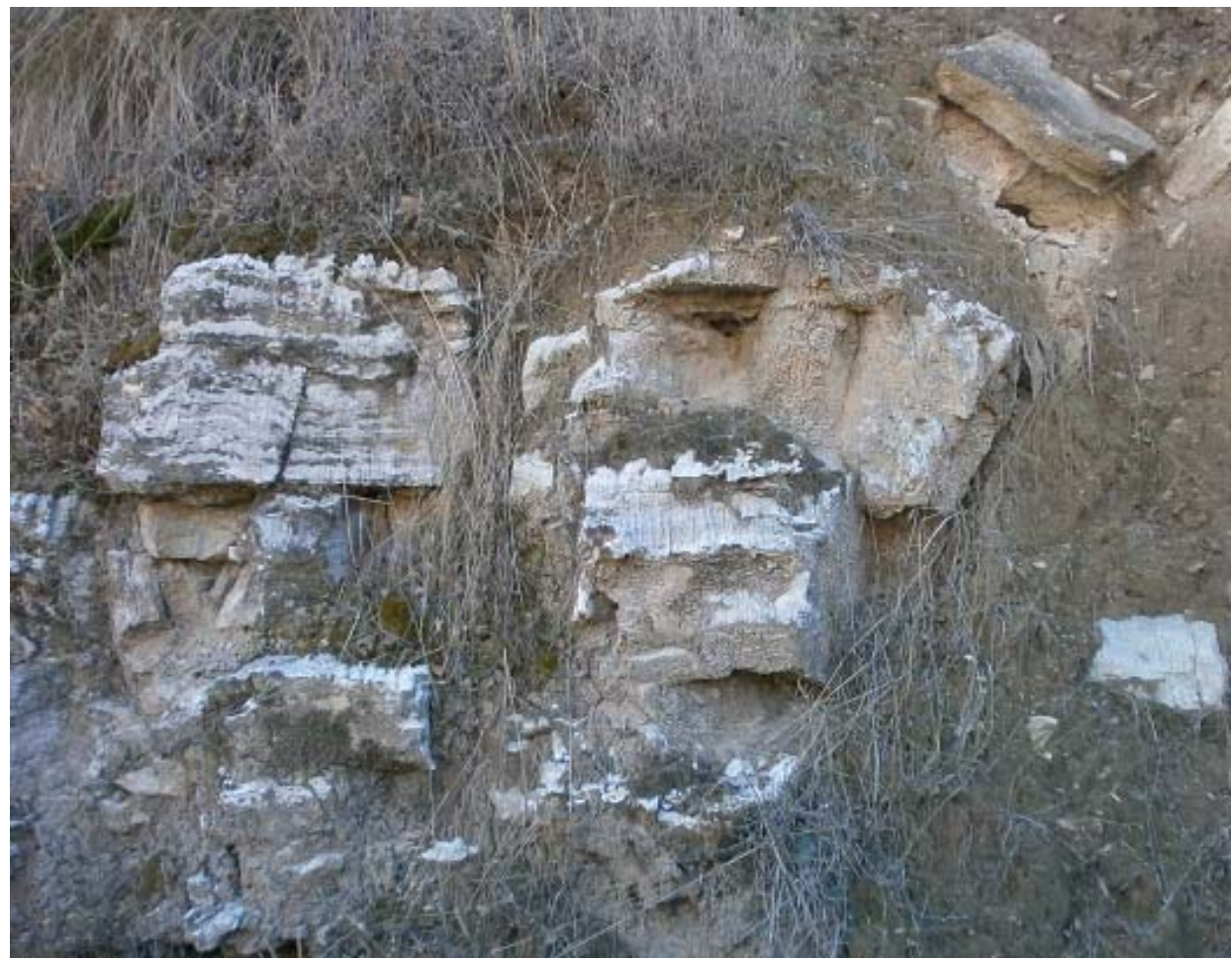

Fotografia 3. Afloraments dels guixos de Clariana, al costat de la carretera, prop del Pla de Rubió

Es molt possible que molt prop d'on som ara, però al terme de Rubió, hi hagi hagut una antiga explotació d'aquests guixos que acabem de veure. Pel que sembla, més amunt de la carretera, al Nord de la mateixa, hi ha una antiga escombrera.

\subsection{Parada 4. IMMEDIACIONS DEL TRENCALL DE CAN PUJOL, Pla de Rubió, terme municipal de Rubió, comarca d'Anoia). (Full 391).}

Després de realitzar la parada anterior, cal continuar el recorregut cap el Nord, seguint la carretera local BV - 1037. Per aquesta ruta, aviat arribarem al caseriu del Pla de Rubió. Poc després trobarem el trencall del vial que es dirigeix cap a l'Espelt. Més endavant arribarem a Can Pau Jordana i després al trencall de Can Pujol. Aquí precisament, podem fer una nova aturada a la bora de la carretera. Així, des de la parada anterior, haurem recorregut prop de 1'5 $\mathrm{Km}$, per tal d'arribar fins aquí.

En aquest recorregut, haurem trobat afloraments dels materials esmentats a les aturades anteriors. Tanmateix, a les parts més baixes s'hauran fet palesos els nivells rogencs de la Formació Artés. Per d'altra banda, haurem estat circulant per una zona més o menys plana. Aquesta correspon a un relieve en cuesta, que no hem arribat a travessar i que es fa molt palès venint des de l'Espelt. Aquesta plana correspon all anomenats Plans d'Ardesa, per on es localitza el caseriu del Pla de Rubió.

En aquest indret, mirant cap a llevant, es poden veure els afloraments dels materials que hem vist a les aturades anteriors. Aquí es troben pels indrets de les Meritxes, per on es fan molt ostensibles els nivells de les calcolutites blanquinoses i els guixos (els anomenats guixos de Clariana). (fotografia 4). 


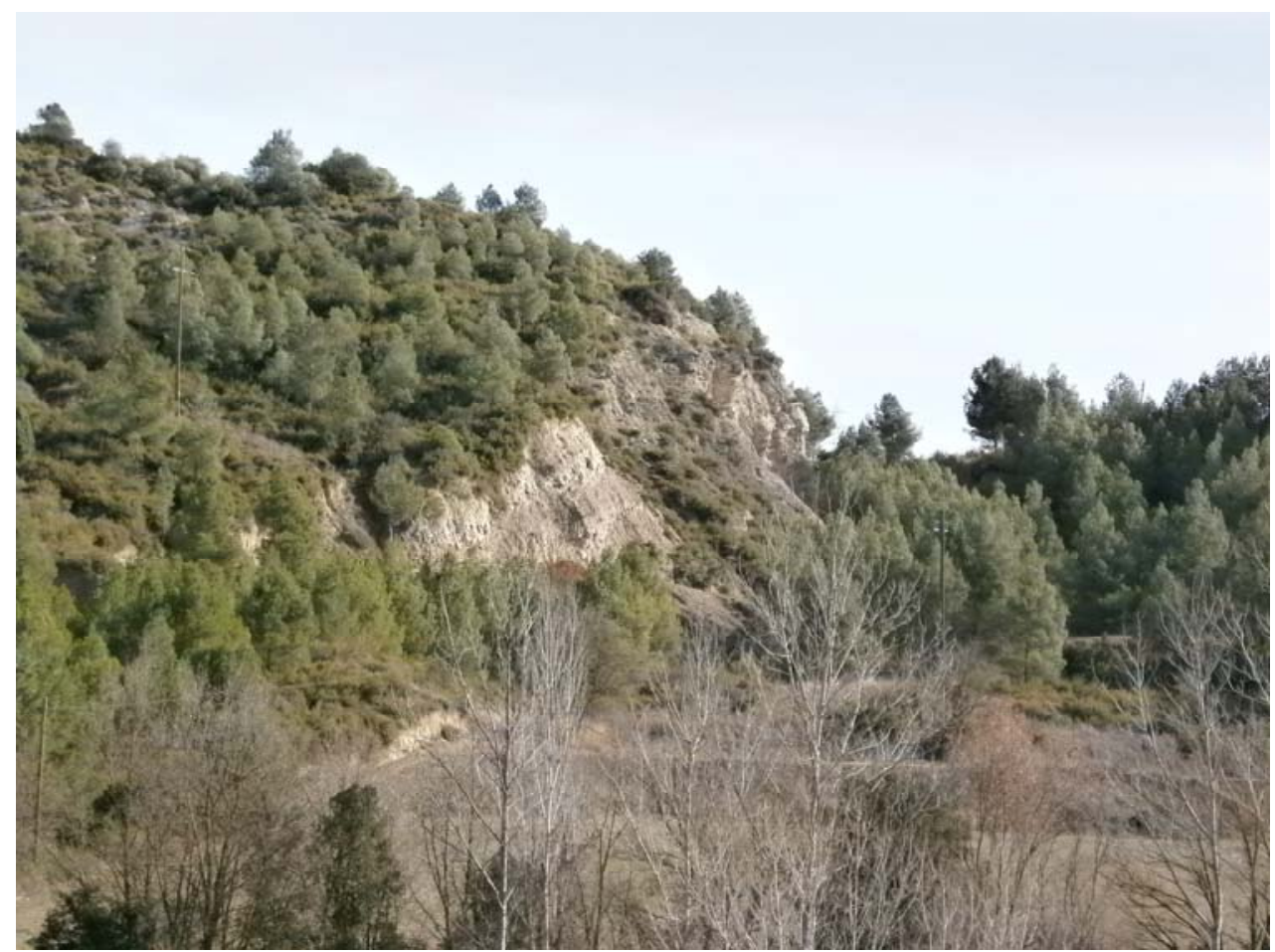

Fotografia 4. Aflorament dels guixos de Clariana (calcolutites i guixos), al Pla de Rubió

La presència dels guixos es fa relativament present a la toponímia de la zona. Així, prop de I'indret anterior hi ha un mas anomenant de Can Guixa.

\subsection{Parada 5. IMMEDIACIONS DEL Km 3’3 DE LA CARRETERA BV - 1037, (terme municipal de Rubió, comarca d'Anoia). (Full 391).}

Després de fer l'aturada anterior, cal fer un nou i breu desplaçament per la carretera que anem seguint, la BV - 1037. Aproximadament, a uns 0’5 Km, podem fer una nova aturada a la bora de la carretera.

En aquest recorregut, hem anat trobant els materials anteriors. Efectivament, a la parada anterior, haurem vist com els materials blanquinosos tenen un lleuger cabussament cap el Nord. (fotografia 5). I ara en circular cap amunt per la carretera, els hem trobat a la bora de la mateixa. Així, ara hi ha un aflorament de guixos al costat de la carretera i també de les calcolutites que hem anat trobant anteriorment, a les aturades anteriors. (fotografia 6). 


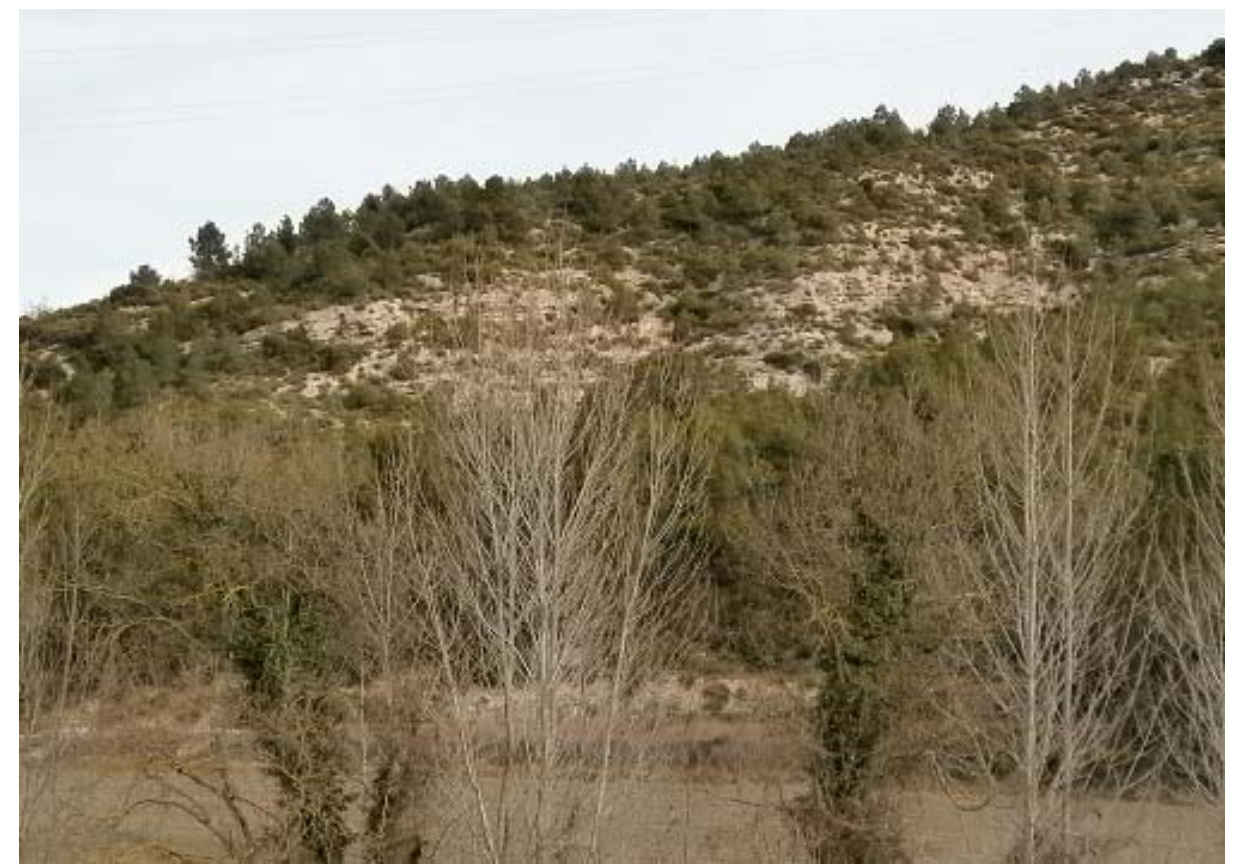

Fotografia 5. Afloraments dels materials blanquinosos dels guixos de Clariana, prop del Pla de Rubió

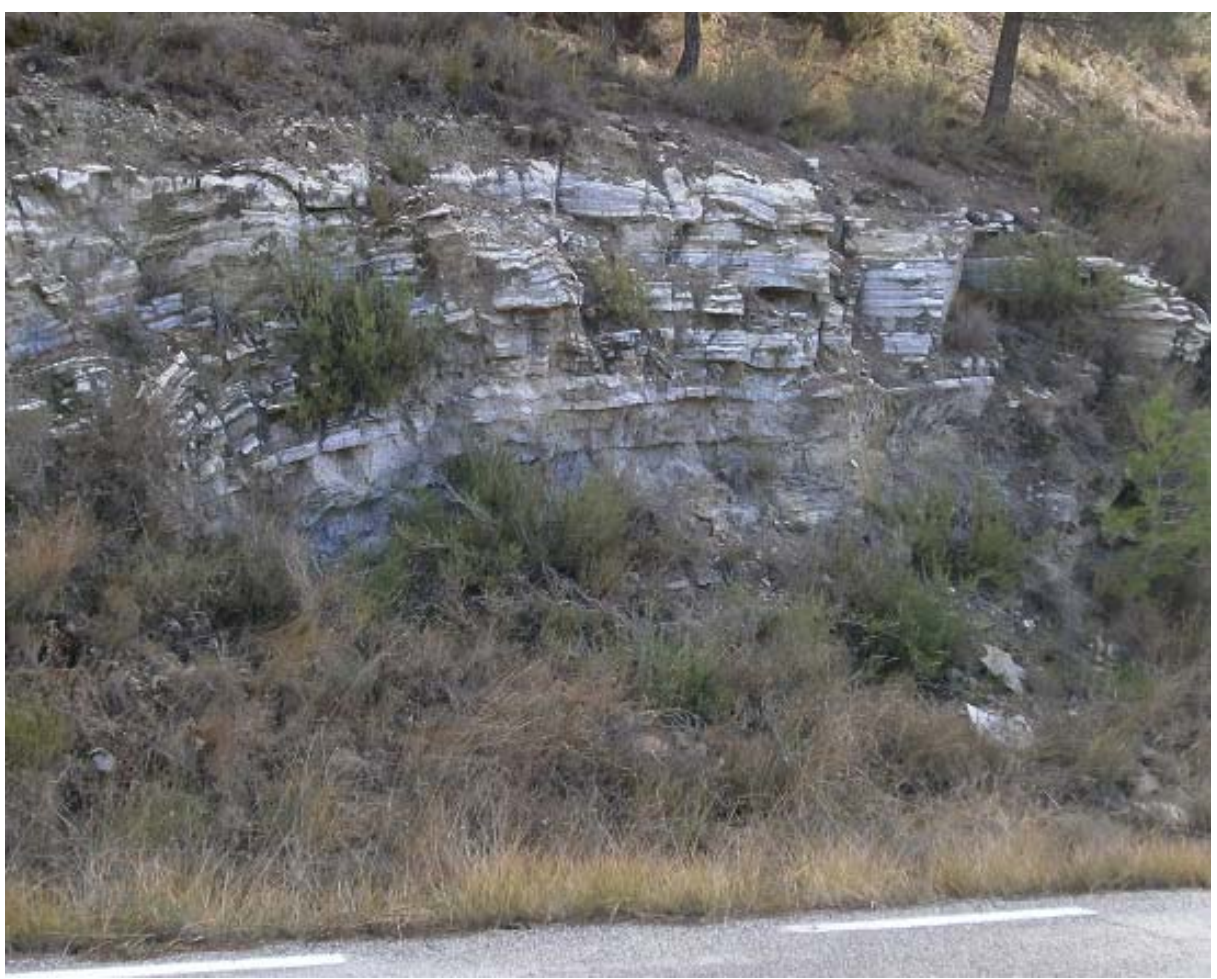

Fotografia 6. Aflorament dels materials anteriors a la bora de la carretera, prop del seu $\mathrm{Km} \mathrm{3} 3$ 


\subsection{Parada 6. MIRADOR DE RUBIÓ, (terme municipal de Rubió, comarca de I’Anoia). (Full 391)}

Després de fer la parada anterior, cal continuar cap amunt, seguint sempre cap a Rubió per la carretera local BV - 1037, En arribar prop del trencall de Ca n'Alzina, podem fer una nova aturada, tot i que és millor fer-la en arribar al poble de Rubió. En arribar-hi, podem fer una nova aturada, prop del Cementiri. Així, des de la parada anterior, haurem recorregut prop de $2^{\prime} 5 \mathrm{Km}$.

En aquest recorregut, hem continuat trobant els materials esmentats a les aturades anteriors. Tot i així, per sobre, haurem vist els materials rogencs de la Formació Artés, amb gresos i calcolutites (margues) de tonalitats vermelles. Aquí, aquests materials són força detrítics i es poden veure freqüents nivells de conglomerats, els quals venen a correspondre a antics paleocanals.

Així, des d'aquest indret, mirant cap a l'altra banda del barranc (la Riera de Rubió) es poden veure aquests paleocanals a l'altra vesant. Tanmateix, a les parts baixes es veuen els nivells més tous que hem acabat d'esmentar. (fotografia 7).

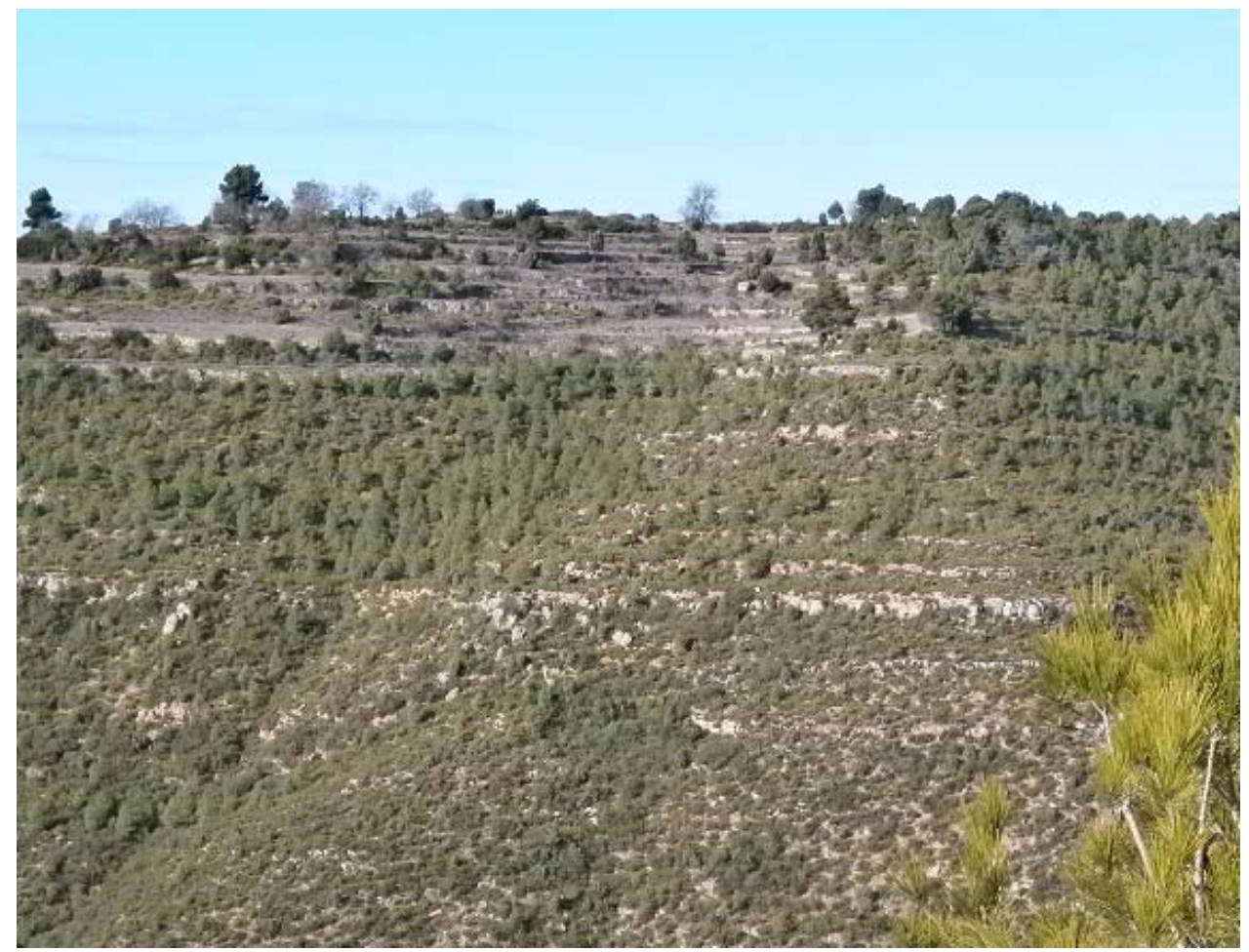

Fotografia 7. Els paleocanals entre els materials de la Formació Artés, enfront de Rubió 


\subsection{Parada 7 - CONDICIONAL. SORTIDA DE RUBIÓ, (terme municipal de Rubió, comarca de I'Anoia). (Full 391)}

Tot seguit, després de fer l'aturada anterior, cal travessar el petit poble de Rubió, per tal de continuar més amunt i de fer una breu aturada a la sortida del poble. Així, haurem recorregut uns 200 metres i escaig.

En fer aquest recorregut, haurem vist com el poblet es situa enlairat sobre un d'aquests paleocanals que hem comentat a l'aturada anterior. Especialment, això es fa pales en veure les restes del castell del poble. (fotografía 8).

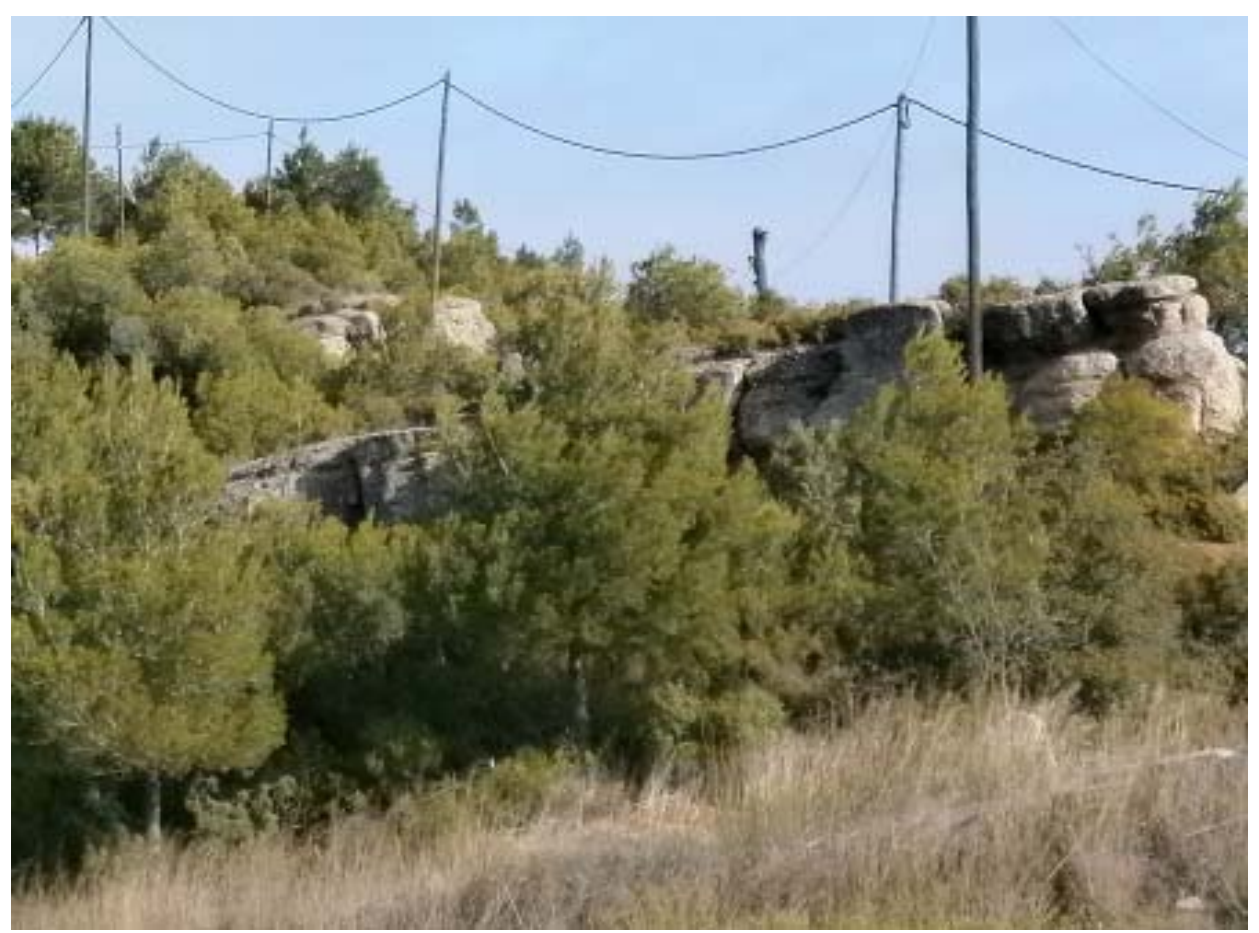

Fotografia 8. Un aspecte d'un d'aquests paleocanals situats entorn a Rubió 


\subsection{Parada 8. IMMEDIACIONS DE LA CRUÏLLA DE LA CARRETERA DE RUBIÓ AMB LA BV - 1031, (terme municipal d’òdena, comarca de I’Anoia). (Full 391)}

Després de fer la parada anterior, cal continuar cap amunt, ara per una carretereta que es dirigeix cap a la propera Serra de Rubió. De fet, aquesta carretereta es dirigeix cap a la carretera local BV - 1031 (que uneix Igualada amb els Prats de Rei). En arribar-hi, farem una nova aturada, la darrera d'aquest itinerari. Així, des de la parada anterior, haurem fet un recorregut molt proper als $4 \mathrm{Km}$.

En aquest recorregut, hem anat trobant els materials que hem esmentat a l'aturada anterior. Aquests materials formen part de la Formació Artés; tot i que ara es fan molt palesos els nivells de conglomerats, sovint constituint paleocanals, de vegades molt potents. Aquests nivells són els que configuren la part alta de la Serra de Rubió, constituint l'esgraó més alt del conjunt de relieves en cuesta, que configurem aquesta serra.

Per d'altra banda, a aquest indret tenim un bon lloc d'observació de la part meridional de la comarca d'Anoia. Així, cap el centre es fa palesa la denominada Conca d'Òdena, per on afloren els materials eocènics que hem vist abans, pels voltants de la ciutat d'Igualada. Més cap el Sud, es fan presents els relleus de la Serralada Prelitoral (on afloren els materials paleozoics de I'Ordovicià i el mesozoics del Triàsic). Tanmateix es pot veure com el riu Anoia travessa aquesta serralada, a través del Congost de Capellades. (fotografia 9).

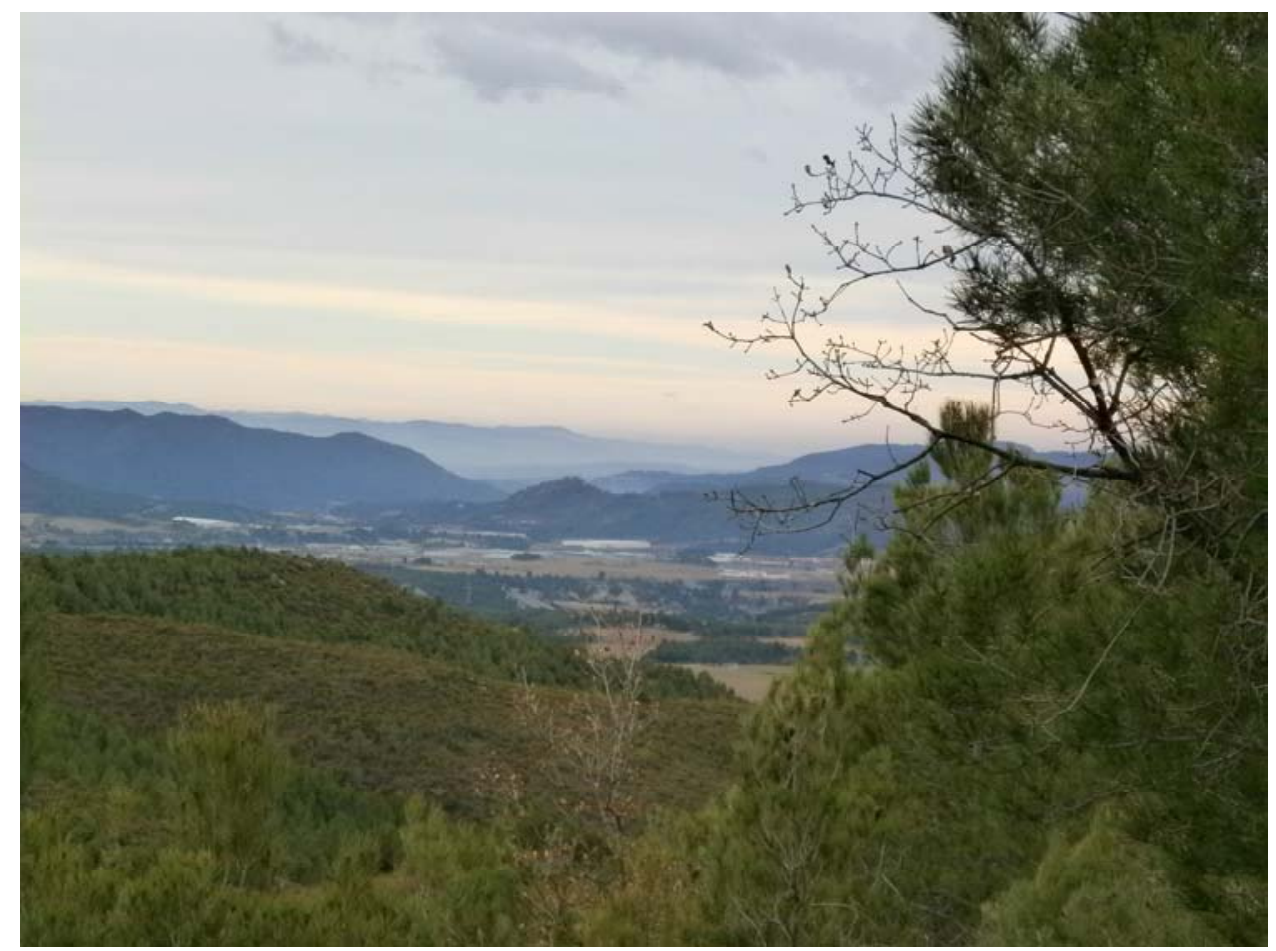

Fotografia 9. La Conca d'Òdena, des de les immediacions del Trencall de Rubió, Carretera BV - 1031

Cap el centre es veuen els materials eocènics que formen la Conca d'Òdena, pels voltants d'Igualada. Al centre es veu el relleu del Castell de la Pobla de Claramunt.

Més lluny es veu la vall del riu Anoia travessant la Serralada Prelitoral

I més lluny s'endevina la Depressió Prelitoral i la Serralada Litoral a l'Horitzó 
En aquest indret finalitza el recorregut de l'itinerari.

\section{Bibliografia}

GUIMERÀ, J. et altri (1992).- Geologia (II), Història Natural dels Països Catalans, Vol.2, 547 pag. Enciclopèdia Catalana, S.A. Barcelona.

MATA - PERELLÓ, J.M. (1985).- Depressió de l'Ebre ?, Depressió Central ?. Revista Dovella, $\mathrm{n}^{\circ} 15$, pp.. 45 - 48. Manresa.

MATA-PERELLÓ, J.M. (1990).- Inventari Mineralògic de la comarca d'Anoia. Revista Xaragall, $\mathrm{n}^{\circ} 24,40$ pag. Manresa.

MATA-PERELLÓ, J.M. (1991).- Els Minerals de Catalunya. Arxius de la Secció de Ciències, t. XCIII, 442 pag. Institut d’Estudis Catalans. Barcelona.

MATA-PERELLÓ, J.M. (1997).- Recerca geològica i mineralògica per les guixeres de la comarca d'Anoia: des d'Ödena i l'Espelt a Jorba i a Clariana. Inèdit, 11 pag. Manresa.

MATA-PERELLÓ, J.M. (1999).- Recerca geològica i mineralògica per la comarca d'Anoia: des d'Òdena i l'Espelt a Jorba, i des de Clariana i Argençola a Bellmunt i Aguiló. Inèdit, 10 pag. Manresa.

MATA-PERELLÓ, J.M. (2000).- Recerca geològica i de reconeixement dels georrecursos per les pedreres de la comarca d'Anoia: des d'Òdena i l'Espelt a Sant Martí de Tous, i des de Clariana i Argençola a Carbassí. Algeps, sèrie B, nº 172, 11 pag. Manresa.

MATA-PERELLÓ, J. M. (2001).- Recerca geològica i geoambiental per les comarques d'Anoia i de la Segarra: des d'Òdena i I'Espelt cap a Sant Genís i Jorba, i des de Montmaneu a Sant Pere dels Arquells. Inèdit, 8 pàgines. Manresa.

MATA-PERELLÓ, J. M. (2012).- Recorregut de recerca geològica i geoambiental per les comarques del Bages, d'Anoia i de la Segarra: des de Maians i Òdena cap a Jorba, la Panadella i a Sant Pere dels Arquells. Inèdit. 14 pàgines. Manresa.

MATA-PERELLÓ, J. M. (2014).- Recorregut de recerca geològica i geoambiental per la comarca d'Anoia: des d'Igualada a la Serra de Rubió, Sant Martí de Maçana, la Manresana i als Prats de Rei. Inèdit. 14 pàgines. Manresa.

RIBA, O. et altri (1976).- Geografia Física dels Països Catalans, Edit. Ketres, 254 pàgines. Barcelona. 